(c) 2020, The Authors. Published by FASS Inc. and Elsevier Inc. on behalf of the American Dairy Science Association ${ }^{\circledR}$. This is an open access article under the CC BY-NC-ND license (http://creativecommons.org/licenses/by-nc-nd/4.0/).

\title{
Metabolic status is associated with the recovery of milk somatic cell count and milk secretion after lipopolysaccharide-induced mastitis in dairy cows
}

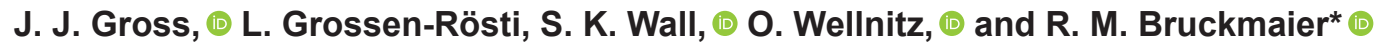 \\ Veterinary Physiology, Vetsuisse Faculty, University of Bern, CH-3012 Bern, Switzerland
}

\begin{abstract}
Infections of the mammary gland in dairy cows are commonly accompanied by reduced milk production and feed intake and poor milk quality. The metabolic status of early-lactating cows is known to affect immune response to pathogens and imposed immune challenges. We investigated the extent to which metabolic status before an intramammary lipopolysaccharide (LPS) challenge (LPS-CH) is associated with immune response, milk production, and feed intake and the recovery thereof. In 15 Holstein cows, weekly blood sampling and daily recording of dry matter intake, milk yield, milk composition, and body weight (to calculate energy balance) was started immediately after parturition. In wk 4 after parturition, cows underwent an intramammary LPS-CH (50 $\mu \mathrm{g}$ of LPS into 1 quarter). Blood and milk samples were taken in parallel at 30- and 60-min intervals, respectively, until $10 \mathrm{~h}$ after the LPS application. Plasma concentrations of glucose, nonesterified fatty acids, $\beta$-hydroxybutyrate (BHB), cortisol, and insulin were analyzed. In milk, serum albumin, IgG concentration, somatic cell count (SCC), and lactate dehydrogenase (LDH) activity were determined. Dry matter intake and milk yield were recorded for an additional 6 d. Milk of the LPS-treated quarter was sampled at every milking for $8 \mathrm{~d}$ after the challenge. Based on plasma glucose concentrations in wk 1 to 4 after parturition before the LPS-CH, cows were retrospectively grouped into a high-glucose group (HG; $3.34-3.93 \mathrm{mmol} / \mathrm{L}, \mathrm{n}$ $=7$ ) and a low-glucose group (LG; $2.87-3.31 \mathrm{mmol} / \mathrm{L}$, $\mathrm{n}=8$ ). Data were evaluated using mixed models with time, group, and time $\times$ group interaction as fixed effects and cow as repeated subject. Glucose was lower and BHB was higher in LG compared with HG before LPS-CH, whereas dry matter intake, energy balance, and SCC did not differ. During LPS-CH, SCC and LDH increased similarly in $\mathrm{HG}$ and LG, body temperature
\end{abstract}

Received December 10, 2019.

Accepted February 9, 2020.

*Corresponding author: rupert.bruckmaier@vetsuisse.unibe.ch increased less in $\mathrm{HG}$, and $\mathrm{BHB}$ and nonesterified fatty acids were higher in LG compared with HG. Dry matter intake declined in both groups during the day of the LPS-CH but recovered to prechallenge values faster in HG. Milk yield recovered within $2 \mathrm{~d}$ after the LPS-CH with no differences in morning milkings, whereas evening milk yield increased faster in HG. During $8 \mathrm{~d}$ after LPS-CH, SCC, LDH, IgG, and serum albumin in milk were lower in HG compared with LG. In conclusion, the level of circulating glucose and BHB concentrations in cows was associated with metabolic responses during an LPS-CH as well as the recovery of udder health and performance thereafter.

Key words: mastitis, recovery, blood-milk barrier, lipopolysaccharide challenge, metabolic status

\section{INTRODUCTION}

Infections of the mammary gland in dairy cows are commonly accompanied by reduced milk production and feed intake and poor milk quality. During mastitis, the integrity of the blood-milk barrier decreases and thus allows for the transfer of blood components (e.g., IgG and serum albumin; SA) into milk. The functionality of the blood-milk barrier is essential to enable milk secretion and prevent blood components from being lost by the lactating animal (Nguyen and Neville, 1998); on the other side, milk components (e.g., lactose) may appear in blood. Characteristically, SCC is elevated in naturally occurring mastitis as well as in experimentally induced immune responses of the mammary gland via LPS (Bruckmaier et al., 1993; Hoeben et al., 2000; Wellnitz and Bruckmaier, 2012). The recovery of the blood-milk barrier after mastitis is crucial to regain milk quality. Several blood constituents, SCC, activity of lactate dehydrogenase (LDH), SA, and IgG present in milk can be used as indicators of the barrier integrity (Wellnitz et al., 2011, 2016). Their decline in milk most likely indicates recovery of mammary gland health. Maintenance of mammary gland health, including a functioning blood-milk barrier, requires energy and nutrients. It is clear that the activation of an immune response requires energy (Ingvartsen and Moyes, 
2015). In addition, the recovery from mastitis can be assumed to be dependent on the availability of energy for the immune system.

The onset of lactation in dairy cows is characterized by a tremendous lack of energy and nutrients (Drackley, 1999; Bruckmaier and Gross, 2017; Gross and Bruckmaier, 2019). Although mobilization of tissue reserves contributes to the maintenance of milk production, the prevailing catabolic state is closely associated with the inflammatory status, making cows most susceptible to metabolic and infectious diseases in the first weeks of lactation (Drackley, 1999; Trevisi et al., 2012; Ingvartsen and Moyes, 2015; Aleri et al., 2016). The uptake of circulating nutrients, particularly glucose, by the lactating mammary gland (Bruckmaier and Gross, 2017; Gross and Bruckmaier, 2019) reduces their availability for relevant immune cells, tissues, and organs (Bauman and Currie, 1980). Glucose is considered the preferred substrate for the immune system (Kvidera et al., 2017), but recent investigations revealed that $\mathrm{BHB}$ also is metabolized in response to immunological challenges (Zarrin et al., 2014; Gross et al., 2018). Concentrations of BHB are typically elevated in early lactation, when circulating free fatty acids derived from lipolysis of depot fat stores exceed hepatic oxidation and reesterification capacity (Grummer, 1993; Brickner et al., 2009; Han van der Kolk et al., 2017). Although the immune system can use ketone bodies as an energy source, cows with high serum nonesterified fatty acid (NEFA) concentration postpartum had an increased incidence of mastitis (Holtenius et al., 2004). This diverse effect may be related to a direct effect of plasma metabolites on immunocompetent cells independent of the energy gain (Targowski and Klucinski, 1983; Suriyasathaporn et al., 1999). Thus, the metabolic status of early-lactating cows as well as the plasma concentrations of various metabolites such as glucose, fatty acids, and ketones directly corresponds to the defense capability of the immune system against pathogens (Vernay et al., 2012; Zarrin et al., 2014). However, most previous research was performed in mid- to late-lactating cows. Recently, Gross et al. (2018) investigated early-lactating cows exposed to an intramammary LPS challenge (LPS-CH).

The recovery from LPS-induced mastitis was occasionally studied in terms of milk production (e.g., Hoeben et al., 2000; Lehtolainen et al., 2003). Until now, less attention was paid to the recovery pattern of performance and reconstitution of udder health and of blood-milk barrier integrity under consideration of the concomitant metabolic status. Therefore, we investigated early-lactating dairy cows with a different metabolic status exposed to an intramammary LPS-CH and followed the recovery of milk production, feed intake, and blood-milk barrier integrity.

\section{MATERIALS AND METHODS}

\section{Animals and Grouping}

Fifteen multiparous Holstein dairy cows were randomly selected from the experimental herd of the Agroscope research station (Posieux, Switzerland). The study design and all experimental interventions followed the Swiss law on animal protection and were approved by the Committee of Animal Experiments of the Canton Fribourg, Switzerland (approval no. 2013_18_FR). Animals were enrolled after parturition and studied until wk 5 after parturition (pp). Throughout the entire study, cows were kept in a tiestall barn and were milked twice daily at 0530 and $1600 \mathrm{~h}$. Cows had free access to water and hay (chemical composition: crude ash, 97 g; CP, $146 \mathrm{~g}$; crude fiber, $246 \mathrm{~g}$; $5.7 \mathrm{MJ}$ of $\mathrm{NE}_{\mathrm{L}} / \mathrm{kg}$ of DM). Concentrate was applied along with a mineral supplement at increasing amounts from 2.8 to $7.3 \mathrm{~kg}$ (as fed) until wk 5 pp.

Based on the 50th percentile of the individual averages of plasma glucose concentrations in wk 1 to $4 \mathrm{pp}$ before the LPS-CH, cows were retrospectively grouped into a high-glucose group $(\mathbf{H G} ; \mathrm{n}=7$; range of average plasma glucose concentration in wk 1 to $4 \mathrm{pp:} 3.34-3.93$ $\mathrm{mmol} / \mathrm{L})$ and a low-glucose group $(\mathbf{L G} ; \mathrm{n}=8$; range of average plasma glucose concentration in wk 1 to $4 \mathrm{pp}$ : $2.87-3.31 \mathrm{mmol} / \mathrm{L})$.

\section{Sampling and Data Recording}

Beginning directly after parturition, milk yields of individual milkings and feed intake were recorded daily (difference of feed supplied minus orts), whereas BW was determined once per week. Dry matter intake was estimated by multiplying the DM content of hay and concentrate with the respective fresh matter intakes. Milk samples from 4 consecutive milkings of 1 wk were pooled proportionally and analyzed for fat, protein, lactose, and urea content by Fourier-transform infrared spectroscopy (MilkoScan FT 6000, Foss Analytical A/S, Hillerød, Denmark). Somatic cell count in weekly composite milk samples was measured using a Fossomatic FC (Foss Analytical A/S). Obtained data were used for calculation of energy balance on a weekly basis for individual animals representing the difference between energy intake and energy requirements for maintenance and milk production. Yield of ECM was calculated using the equation given by Sjaunja et al. (1990):

$$
\begin{gathered}
{[(0.038 \times \mathrm{g} \text { of fat } / \mathrm{kg} \text { of milk }+0.024 \times \mathrm{g} \text { of } \mathrm{CP} /} \\
\mathrm{kg} \text { of milk }+ \\
0.017 \times \mathrm{g} \text { of lactose } / \mathrm{kg} \text { of milk }) \\
\times \mathrm{kg} \text { of milk }] / 3.14 .
\end{gathered}
$$


Blood sampling from the jugular vein was performed once weekly between 0800 and $0900 \mathrm{~h}$ after milking and before feeding using evacuated EDTA-coated tubes (Vacuette, Greiner Bio One, Frickenhausen, Germany). Blood samples in HG were obtained at $3.6 \pm 1.0$ DIM (mean \pm SD; range: $2-5$ DIM) in wk $1,11.0 \pm 2.2 \mathrm{DIM}$ (range: $7-13$ DIM) in wk 2, $16.6 \pm 2.4$ DIM (range: 13-19 DIM) in wk 3, and 24.6 \pm 2.6 DIM (range: $20-27$ DIM) in wk 4. Blood samples in LG were obtained at $3.8 \pm 1.0$ DIM (mean \pm SD; range: $2-5$ DIM) in wk $1,10.0 \pm 3.0$ DIM (range: $6-14$ DIM) in wk 2, $16.1 \pm$ 2.3 DIM (range: $13-19$ DIM) in wk 3, and $23.0 \pm 2.7$ DIM (range: 20-26 DIM) in wk 4. Samples were kept on wet ice and centrifuged at $3,000 \times g\left(+4^{\circ} \mathrm{C}, 20 \mathrm{~min}\right)$, and the harvested plasma was stored at $-20^{\circ} \mathrm{C}$ until analysis.

\section{Intramammary LPS-CH and Sampling Thereafter}

Before the intramammary LPS-CH in wk $4 \mathrm{pp}$, a consistent low SCC $(<150,000$ cells $/ \mathrm{mL})$ and absence of clinical mastitis symptoms for $3 \mathrm{~d}$ leading up to the experimental day were required. Shortly after the morning milking at $0600 \mathrm{~h}, 1$ rear quarter was injected via the teat canal with $50 \mu \mathrm{g}$ of LPS (from Escherichia coli serotype O26:B6, Sigma-Aldrich, St. Louis, MO) dissolved in $10 \mathrm{~mL}$ of $0.9 \% \mathrm{NaCl}$ solution. Milk samples from the LPS-treated quarter were taken hourly until the afternoon milking at $1600 \mathrm{~h}$. Milk SCC was directly determined with a DeLaval cell counter (DeLaval International AB, Tumba, Sweden). Blood samples were frequently obtained from a jugular vein catheter (every 30 min from 0600 to $1400 \mathrm{~h}$; thereafter every $60 \mathrm{~min}$ until $1600 \mathrm{~h}$ ). Concomitantly to the blood samples, cows were examined by a veterinarian (e.g., body temperature, heart and respiratory rate, udder and teat conformation). Milk samples $(\sim 5 \mathrm{~mL})$ during the recovery period were hand-stripped into tubes from the challenged quarter (starting at the morning milking on $\mathrm{d}+1$ after challenge) for a further $8 \mathrm{~d}$ ( 15 milkings) postchallenge. Aliquots of milk and blood plasma were frozen at $-20^{\circ} \mathrm{C}$ until further analysis. Milk yield and DMI were followed for $6 \mathrm{~d}$ following the LPS-CH.

\section{Analysis of Metabolites, Endocrine Factors, and Proteins in Plasma and Milk}

Concentrations of plasma metabolites (glucose, NEFA, and BHB) were determined enzymatically using commercial kits with an automatic analyzer (Cobas Mira 2, Hoffmann-La Roche, Basel, Switzerland) as described earlier by Gross et al. (2011a). Insulin concentrations were analyzed using RIA (for further details and assay descriptions, see Vicari et al., 2008;
Gross et al., 2011b). Inter- and intra-assay coefficients of variation for insulin were 7.8 and $8.9 \%$, respectively. Plasma cortisol concentrations were measured with RIA as described in more detail by Blum et al. (1985) and Schwinn et al. (2016); however, due to technical reasons, they were measured only for the first $5.5 \mathrm{~h}$ after LPS application. Inter- and intra-assay coefficients of variation for cortisol were 8.4 and $9.2 \%$, respectively.

In milk samples, concentrations of IgG and SA were measured using commercially available ELISA kits (bovine specific; Bethyl Laboratories, Montgomery, TX) according to the manufacturer's instructions with modifications as stated in Lehmann et al. (2013). Interand intra-assay coefficients of variation for IgG were 3.9 and $4.1 \%$, respectively, and for SA were 4.3 and $5.4 \%$, respectively. For LDH measurement, milk serum was obtained using a 2-step process (centrifugation at $4,000 \times g, 15 \mathrm{~min},+4^{\circ} \mathrm{C}$; then $14,000 \times g$ for $30 \mathrm{~min}$ at $+4^{\circ} \mathrm{C}$ ) and then measured with a commercial kit (LDH IFCC, Axon Lab AG, Baden, Switzerland) using an automated analyzer (Cobas Mira 2, Hoffmann-La Roche) according to the manufacturer's instructions.

\section{Statistical Analysis}

Data presented in the manuscript are means \pm standard errors of the mean. Statistical evaluations were carried out with the statistical program package SAS (version 9.4; SAS Institute Inc., Cary, NC). Data were checked for normal distribution using PROC UNIVARIATE. Data of SCC were log-transformed $\left(\log _{10}\right)$. All data were evaluated with PROC MIXED using mixed models with time, group, and time $\times$ group interaction as fixed effects and cow as repeated subject. Pairwise LSM comparisons produced from the interaction term estimates were adjusted using Bonferroni-corrected $t$-tests, and significant effects were considered at $P$ values $<0.05$.

\section{RESULTS}

\section{Metabolic Status, Milk Yield, and DMI Before LPS-CH}

Milk yield and DMI increased in both groups from wk 1 to 4 pp (Figure 1A and B). With increasing DMI, energy balance alleviated but was still negative at the end of the study (Figure 1C). Milk yield, DMI, and energy balance were not different between $\mathrm{HG}$ and LG in the early-lactation period before the LPS-CH $(P=$ $0.25,0.49$, and 0.13 , respectively; Figure 1 ).

Due to the retrospective grouping according to plasma glucose concentrations in wk 1 to 4 pp before the LPS$\mathrm{CH}$, cows of the HG group had a higher glucose concentration in plasma than cows of the LG group (Figure 

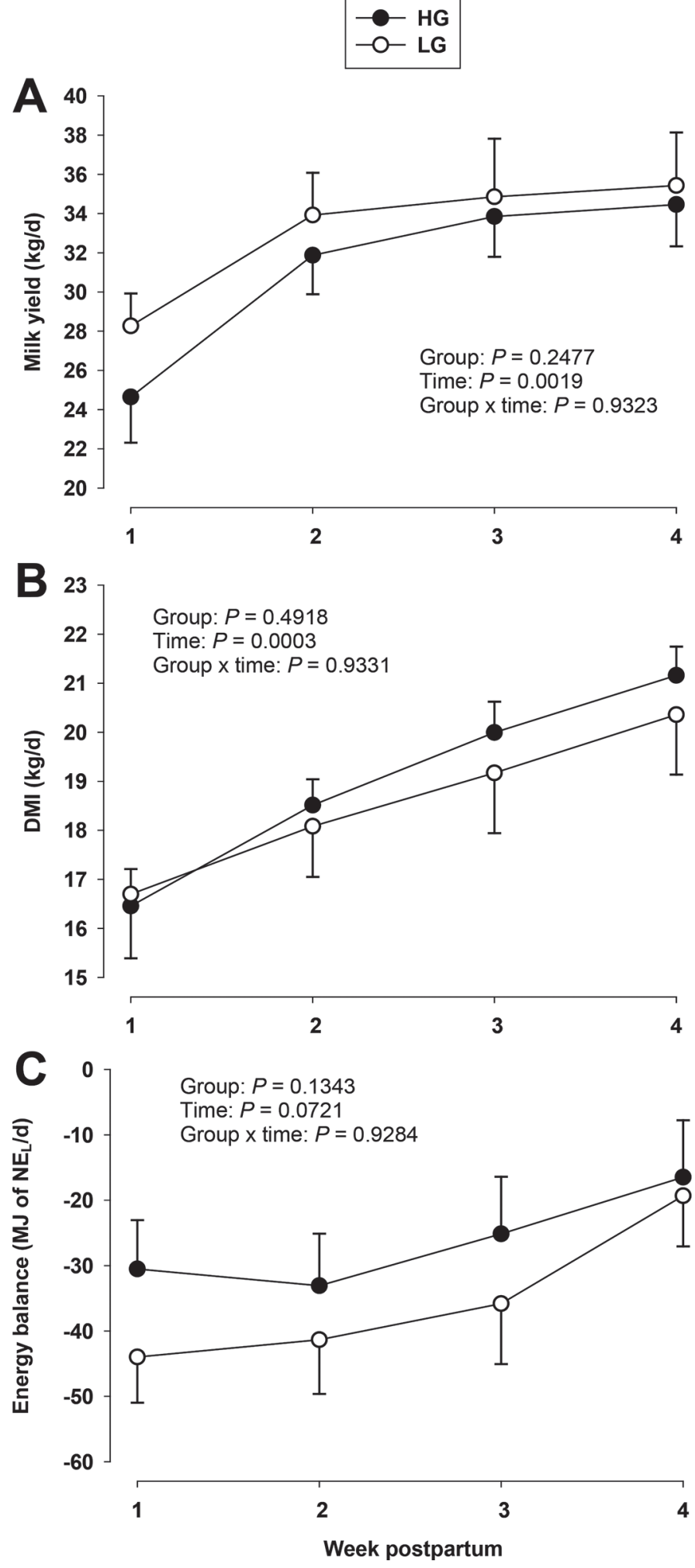

Figure 1. (A) Milk yield, (B) DMI, and (C) energy balance in dairy cows assigned to the low-glucose (LG; $\mathrm{n}=8)$ and high-glucose $(\mathrm{HG} ; \mathrm{n}=7$ ) groups during wk 1 to 4 postpartum. Data are presented as means \pm SEM.

Journal of Dairy Science Vol. 103 No. 6, 2020
$2 \mathrm{~A} ; P<0.0001)$. Plasma concentration of NEFA was only higher in LG in wk 2 pp compared with HG (Figure $2 \mathrm{~B}$ ). Besides differences in glucose concentrations, LG concomitantly showed higher plasma BHB concentrations up to wk 4 pp compared with $\mathrm{HG}$, indicating a higher metabolic load (Figure 2C; $P<0.01$ ). Plasma insulin concentration and milk gross composition (fat, protein, and lactose contents) were not different among groups throughout the study period (data not shown). Milk SCC was similar in HG and LG (Figure 3A; $P$ $=0.26)$, whereas milk urea content was higher in LG compared with HG (Figure 3B; $P=0.04$ ).

\section{Metabolic and Inflammatory Responses and Blood- Milk Barrier Integrity During LPS-CH}

Following a time lag of approximately 2 to $3 \mathrm{~h}$ after the intramammary LPS injection, rectal temperature increased similarly in both groups to a maximum of $41.5 \pm 0.2^{\circ} \mathrm{C}$ at 5 to $6 \mathrm{~h}$ after LPS application (data not shown). Concomitantly with rectal temperature, plasma concentrations of cortisol and insulin increased. No differences in cortisol and insulin concentrations were detected between LG and HG $(P=0.50$ and 0.33 , respectively). During the LPS-CH, there was no group effect on plasma concentration of glucose $(P=0.34)$, whereas NEFA and BHB were higher in LG compared with HG $(P<0.001$ and 0.03 , respectively). Data on changes in glucose, NEFA, BHB, and insulin are shown in Figure 4.

Milk SCC increased and reached its maximum at approximately $7 \mathrm{~h}$ after LPS application in instilled mammary quarters (Figure 5A). No differences for SCC were detected between LG and $\mathrm{HG}$ on the day of the LPS-CH $(P=0.52)$. Activity of LDH in milk increased slightly late compared with the observed SCC increase (Figure 5B) but without an effect related to grouping according to glucose concentration $(P=0.51)$. Concentration of SA in milk increased between 2 and $3 \mathrm{~h}$ after LPS application, reaching a plateau at 4 to $5 \mathrm{~h}$ relative to the start of the LPS-CH, and decreased thereafter (Figure 5C). No differences between LG and HG were detected.

\section{Recovery Pattern of Performance and Reconstitution of the Blood-Milk Barrier}

A sharp decline in milk yield was observed at the day of the LPS-CH (Figure 6A). Total daily milk yield reached prechallenge values (reference: average of $\mathrm{d} 5$ to 1 before the LPS-CH) again on d 2 after the LPS$\mathrm{CH}$. Only morning milk yield of the first day after the challenge was decreased in LG and HG (Figure 6B; $P$ $<0.05$ ); the most marked decrease was observed for the 

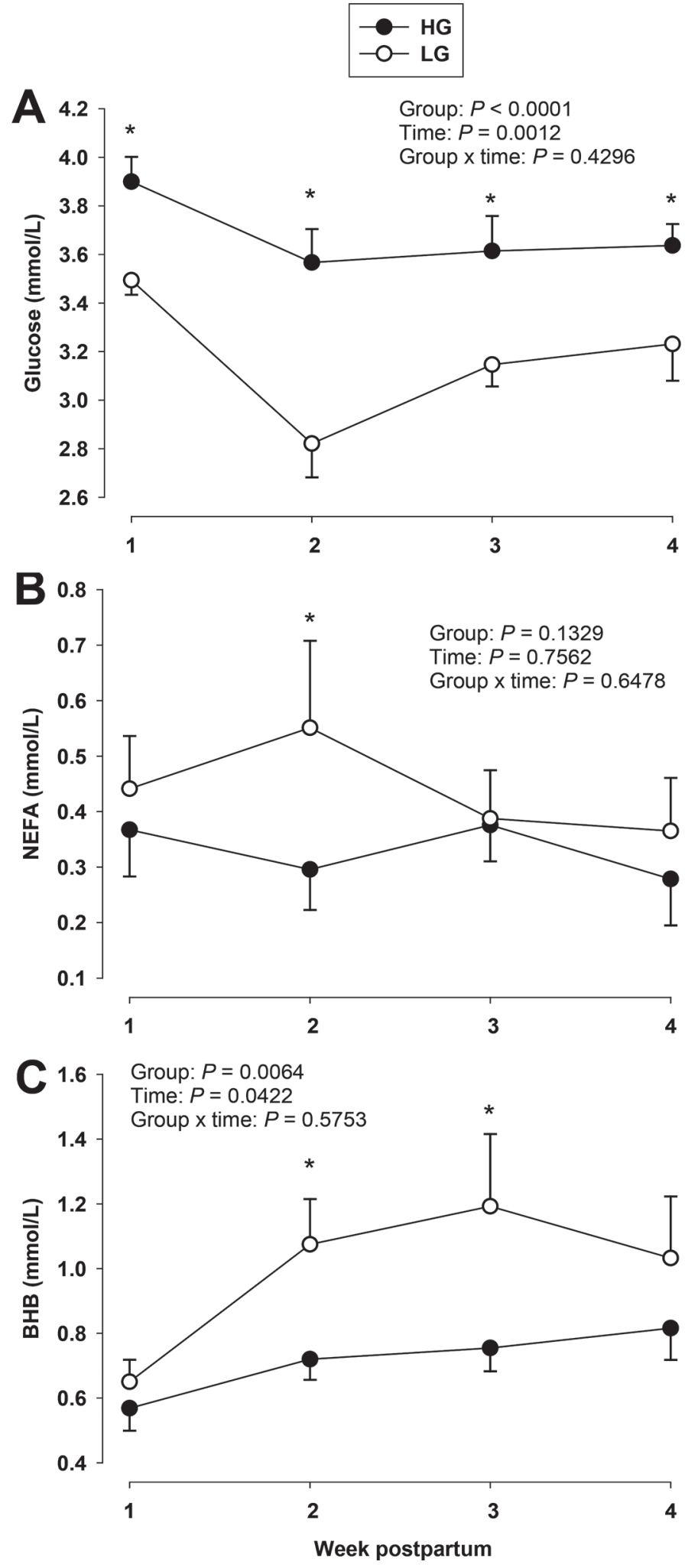

Figure 2. Plasma concentrations of (A) glucose, (B) nonesterified fatty acids (NEFA), and (C) BHB in dairy cows assigned to the low-glucose (LG; $\mathrm{n}=8)$ and high-glucose $(\mathrm{HG} ; \mathrm{n}=7)$ groups during wk 1 to 4 postpartum. Data are presented as means \pm SEM. Asterisk indicates differences within a week between LG and HG $(P<0.05)$.

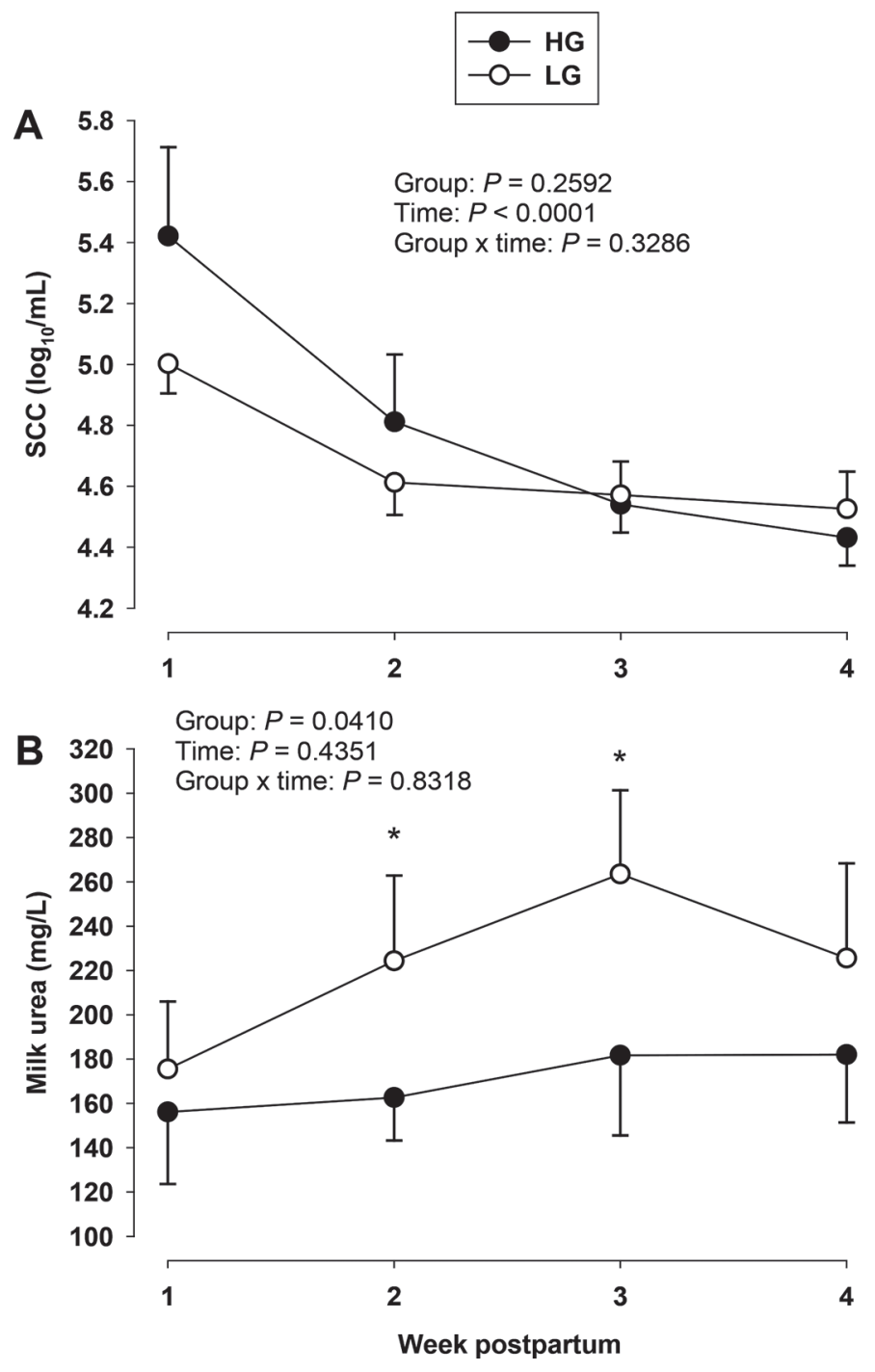

Figure 3. (A) Milk SCC and (B) milk urea concentration in dairy cows assigned to the low-glucose $(\mathrm{LG} ; \mathrm{n}=8)$ and high-glucose (HG; $\mathrm{n}=7$ ) groups during wk 1 to 4 postpartum. Data are presented as means \pm SEM. Asterisk indicates differences within a week between LG and HG $(P<0.05)$.

evening milk yield at the day of the LPS-CH (Figure $6 \mathrm{C})$. Milk yield of the first evening milking on the day of challenge was decreased in both LG and HG compared with prechallenge values, whereas HG recovered faster and reached prechallenge milk production on the first day following the LPS-CH (Figure 6C; $P<0.05$ ). Evening milk yield of LG achieved prechallenge levels only on d 2 (Figure 6C). Similar to milk production, DMI decreased in both LG and HG at the day of the LPS-CH (Figure 7A). Whereas HG consumed similar amounts of feed on the first day after the challenge as observed before the immune stimulation, LG required 1 $\mathrm{d}$ more to recover in DMI (Figure 7B; $P<0.05$ ). 
The reconstitution of the blood-milk barrier integrity after the LPS-CH lasted several days. Although no group differences were observed at the challenge day itself, SCC in milk continuously decreased and tended to be lower in HG than in LG in the days following the LPS-CH, indicating a faster recovery of udder health in $\mathrm{HG}$ (Figure $8 \mathrm{~A} ; P=0.06$ ). Activity of LDH in milk was higher in LG compared with HG during the recovery period (Figure 8B; $P<0.01$ ). Concentration of IgG in milk was higher in LG only at the first morning milking after the LPS-CH $(P<0.05)$ and decreased until d 4 after the immune challenge (Figure $8 \mathrm{C}$ ). Serum albumin concentration was elevated in milk of LG compared with HG only at the first day postchallenge $(P<$ $0.05)$ and higher by trend including all observations for the $8 \mathrm{~d}$ postchallenge (Figure $8 \mathrm{D} ; P=0.08$ ).

\section{DISCUSSION}

\section{Associations of Metabolic Status with Immediate Responses to LPS-CH}

Low glucose and elevated BHB concentrations before the LPS-CH in the present study persisted throughout the day of the intramammary LPS-CH, although initial differences in plasma glucose concentrations diminished during the inflammatory response. The release of cortisol and temporary development of insulin resistance are characteristic adaptations to inflammation aiming at maximizing nutrient supply for the immune system via elevation of circulating glucose (Vernay et al., 2012; Zarrin et al., 2014; Gross et al., 2018). In the present study, both LG and HG cows were in early lactation
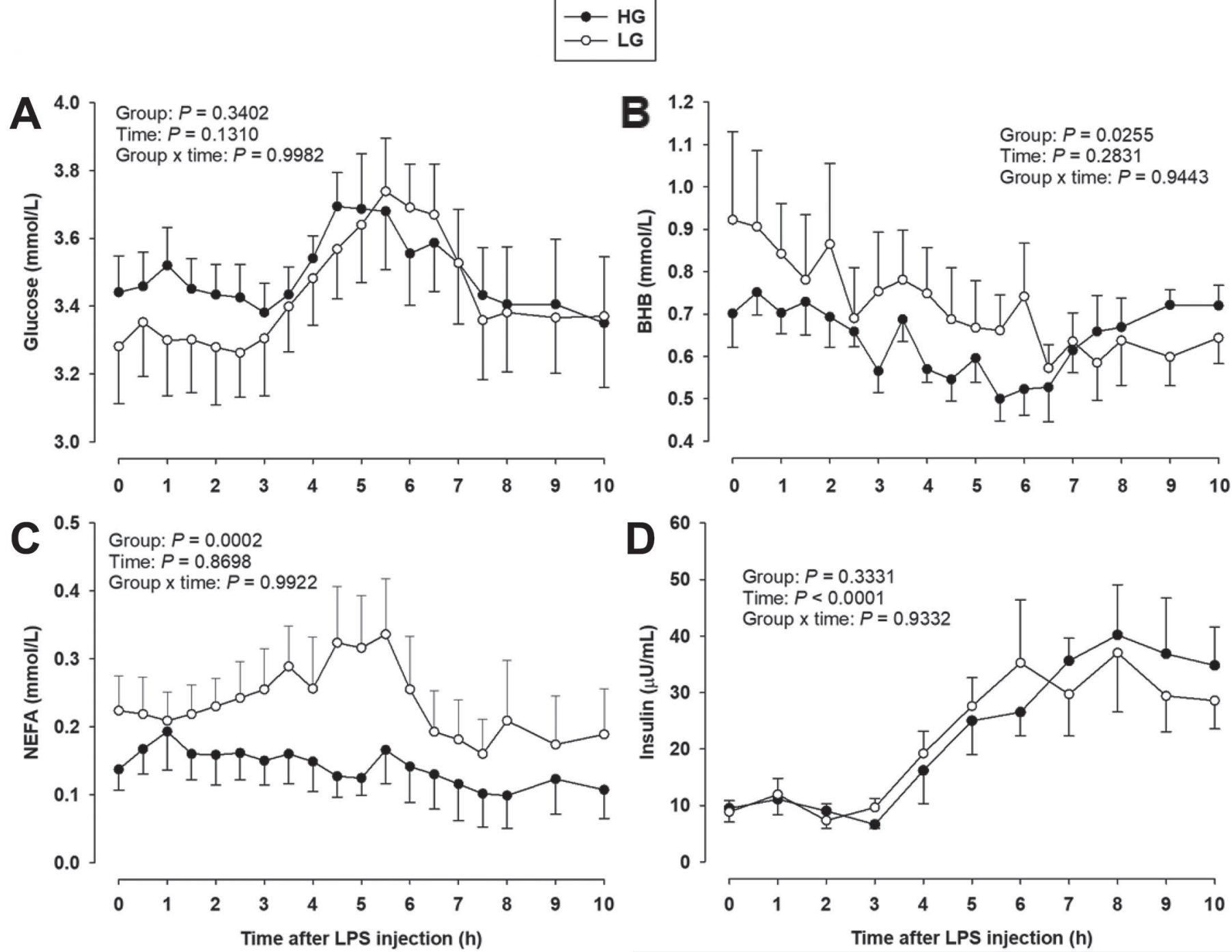

Figure 4. Plasma concentrations of (A) glucose, (B) BHB, (C) nonesterified fatty acids (NEFA), and (D) insulin in dairy cows assigned to the low-glucose (LG; $\mathrm{n}=8)$ and high-glucose $(\mathrm{HG} ; \mathrm{n}=7)$ groups during the LPS challenge day. Data are presented as means \pm SEM. 

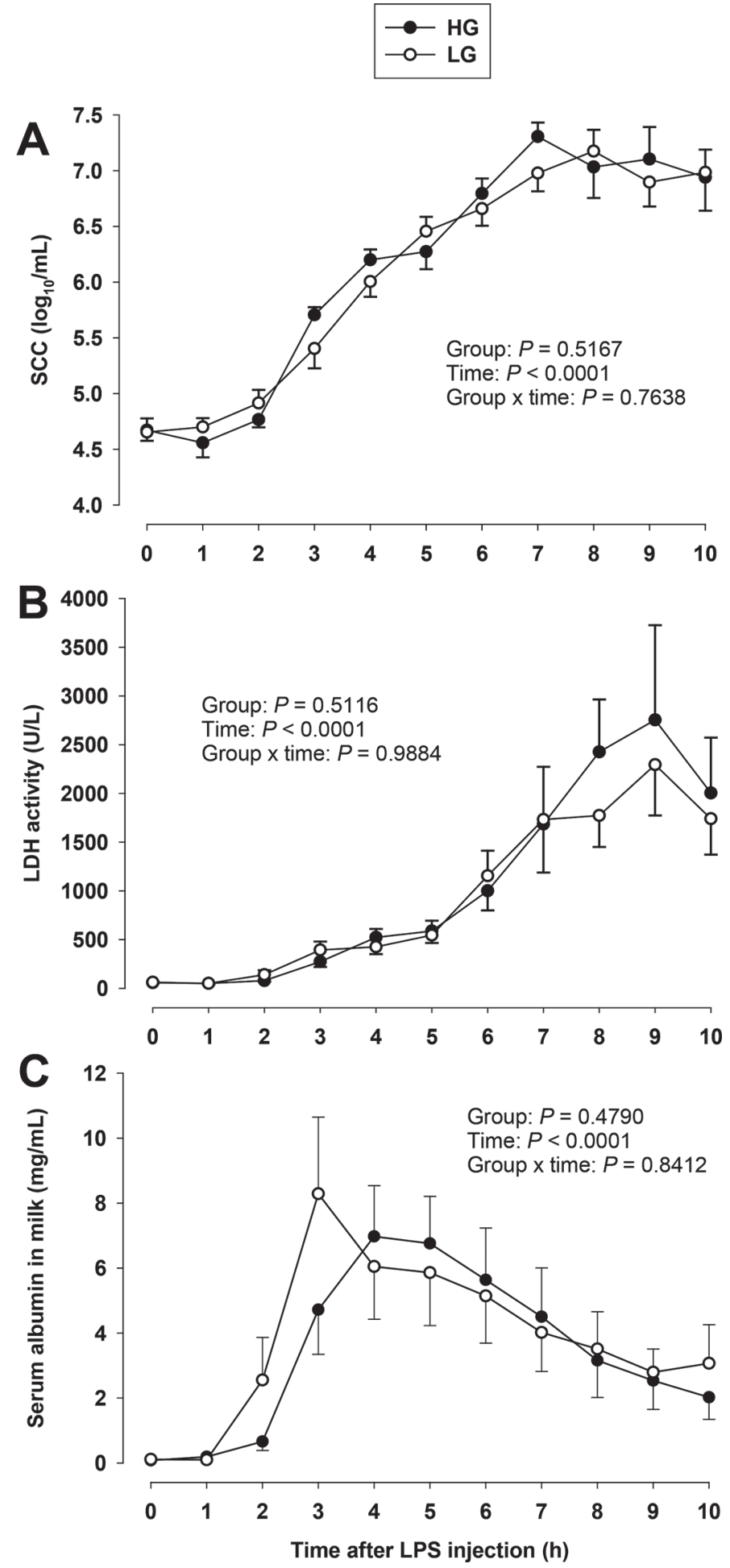

Figure 5. (A) Somatic cell count, (B) activity of lactate dehydrogenase $(\mathrm{LDH})$, and $(\mathrm{C})$ serum albumin concentration in milk of the LPS-stimulated quarter in dairy cows assigned to the low-glucose (LG; $\mathrm{n}=8)$ and high-glucose (HG; $\mathrm{n}=7)$ groups. Data are presented as means \pm SEM.
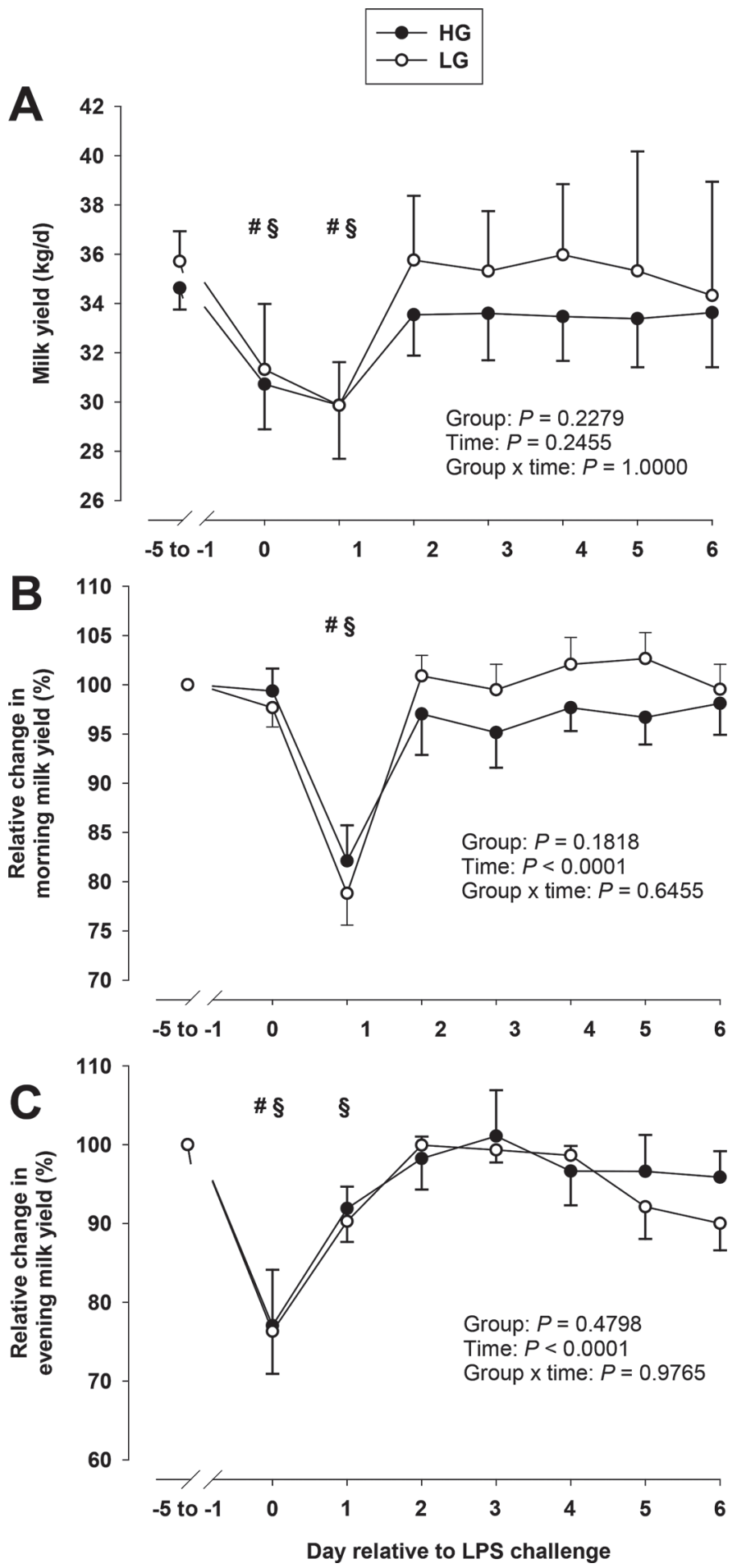

Figure 6. (A) Milk yield and changes in the (B) morning and (C) evening milkings during the $6 \mathrm{~d}$ following the intramammary LPS challenge in dairy cows assigned to the low-glucose (LG; $n=8)$ and high-glucose (HG; $\mathrm{n}=7$ ) groups. Data are presented as means \pm SEM. Significant changes within a group at the respective days relative to the initial values (average $\mathrm{d}-5$ to -1 ) before the LPS challenge are indicated with \# for HG and $\S$ for LG. 
and had a negative energy balance before the LPS$\mathrm{CH}$. The induction of a negative energy balance and a concomitant ketotic status by feed restriction increased the severity of responses to an experimental E. coli mastitis (Kremer et al., 1993). In contrast to the study of Kremer et al. (1993) with lower glucose and greater BHB concentrations, cows in the LG group in the present study experienced only mild hyperketonemia close to the thresholds of subclinical ketosis (Suthar et al., 2013; Brunner et al., 2019). This could explain why acute responses to the intramammary LPS-CH did not differ between groups in our study, and cows of the
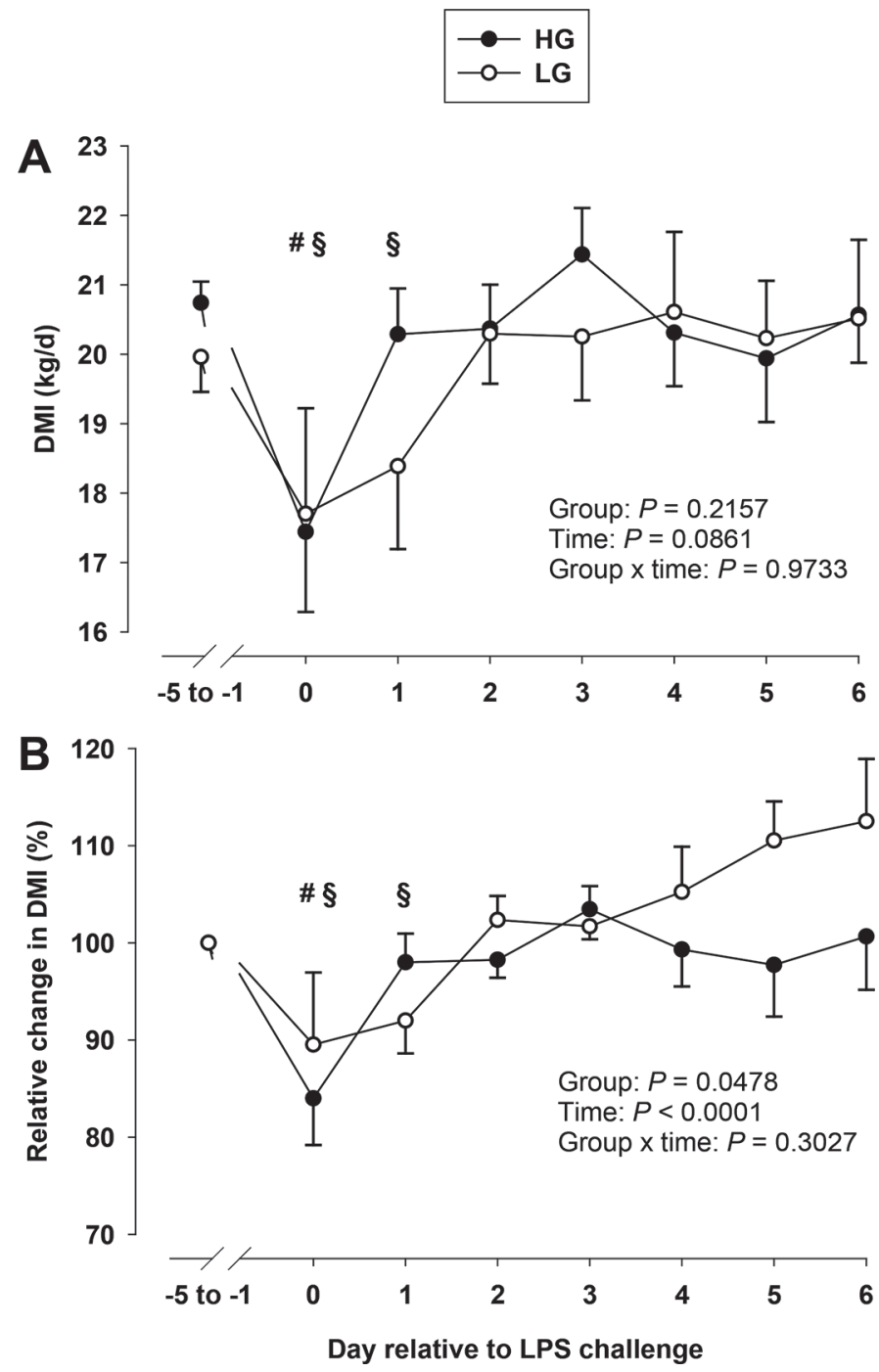

Figure 7. (A) Dry matter intake and (B) changes in DMI during the $6 \mathrm{~d}$ following the intramammary LPS challenge in dairy cows assigned to the low-glucose (LG; $\mathrm{n}=8$ ) and high-glucose (HG; $\mathrm{n}=$ 7) groups. Data are presented as means \pm SEM. Significant changes within a group at the respective days relative to the initial values (average $\mathrm{d}-5$ to -1 ) before the LPS challenge are indicated with \# for $\mathrm{HG}$ and $\S$ for LG. poorer metabolic condition could clearly cope well with the short-term challenge. Our results are supported by observations in mid-lactation cows from Perkins et al. (2002). Although Perkins et al. (2002) induced a catabolic status before an LPS-CH through feed restriction, acute clinical symptoms following the intramammary endotoxin application were not altered compared with cows maintaining a positive energy balance. Undernutrition before an LPS-CH in early lactation in the study of Pires et al. (2019) triggered metabolic differences in glucose, NEFA, and BHB concentrations that persisted in a similar manner to our findings throughout the day of the LPS-CH but also with limited effects on inflammation markers. In contrast, an earlier study by Vandeputte-Van Messom et al. (1993) showed that cows retrospectively classified as either moderate or severe responders to an experimental E. coli mastitis differed in their blood and milk composition before the infection, where severe responders had lower glucose concentrations. Nevertheless, there is a considerable risk of infectious diseases due to metabolic stress in early lactation as host defense mechanisms might be compromised (Sordillo et al., 2009). Excessive adipose tissue lipolysis during negative energy balance results in elevated concentrations of NEFA that in turn cause oxidative stress and elevated circulating ketone bodies and, hence, suppress inflammatory responses (Suriyasathaporn et al., 1999). Elevated concentrations of NEFA were shown to activate Toll-like receptors and their mediated signaling pathways involved in immune responses (Lee et al., 2003). Similarly, cows fed above their requirements and consequently getting overconditioned during the dry period showed greater concentrations of NEFA and an altered immune response to an intramammary LPS-CH after parturition (Graugnard et al., 2013). We observed elevated urea concentrations in the milk of cows with poorer metabolic condition. Because urea concentrations in milk are closely related to urea concentrations in blood (DePeters and Ferguson, 1992; Gustafsson and Palmquist, 1993), our results suggest that the energy-demanding elimination of urea is impaired in LG cows. Furthermore, urea was shown to increase oxidative stress in blood polymorphonuclear neutrophils (Tsunoda et al., 2017) and thus impair the immune competence of animals.

\section{Associations of Metabolic Status with the Decline and Recovery Pattern of Milk Yield, Feed Intake, and Reconstitution of the Blood-Milk Barrier Following LPS-CH}

Naturally occurring mastitis as well as experimentally induced mammary inflammatory conditions are accompanied by reduced animal performance (i.e., de- 
creased DMI and milk yield; Zamet et al., 1979; Potter et al., 2018). Besides the appearance and severity of mastitis (subacute or acute), the pathogen responsible for the inflammation and the concomitant metabolic status particularly affect changes in milk yield and composition (Oliver and Calvinho, 1995; Moyes, 2015). In experimental studies infusing the bacterial endotoxin LPS into the mammary gland, milk yield decreased markedly and recovered at the second day after the challenge (Hoeben et al., 2000; Lehtolainen et al., 2003). However, milk production is reduced not only in the quarter infused with LPS but also, to a lesser extent, in untreated quarters (Shuster et al., 1991; Bruckmaier et al., 1993). Shuster et al. (1991) reported a decline of milk yield by more than $30 \%$ in quarters infused with LPS at the second milking following the LPS infusion, whereas noninfused quarters had almost returned to their normal production. Although we did not determine milk yield at the individual-quarter level, our results indicate a partial recovery of milk yield already at the second milking following the LPS infusion in the HG group, whereas cows with the poorer metabolic condition before the LPS-CH returned more slowly to initial production. Likewise, cows responding more severely to an experimental E. coli mastitis and having less circulating glucose showed a more pronounced decrease in $\multimap$ HG
$\multimap-$ LG
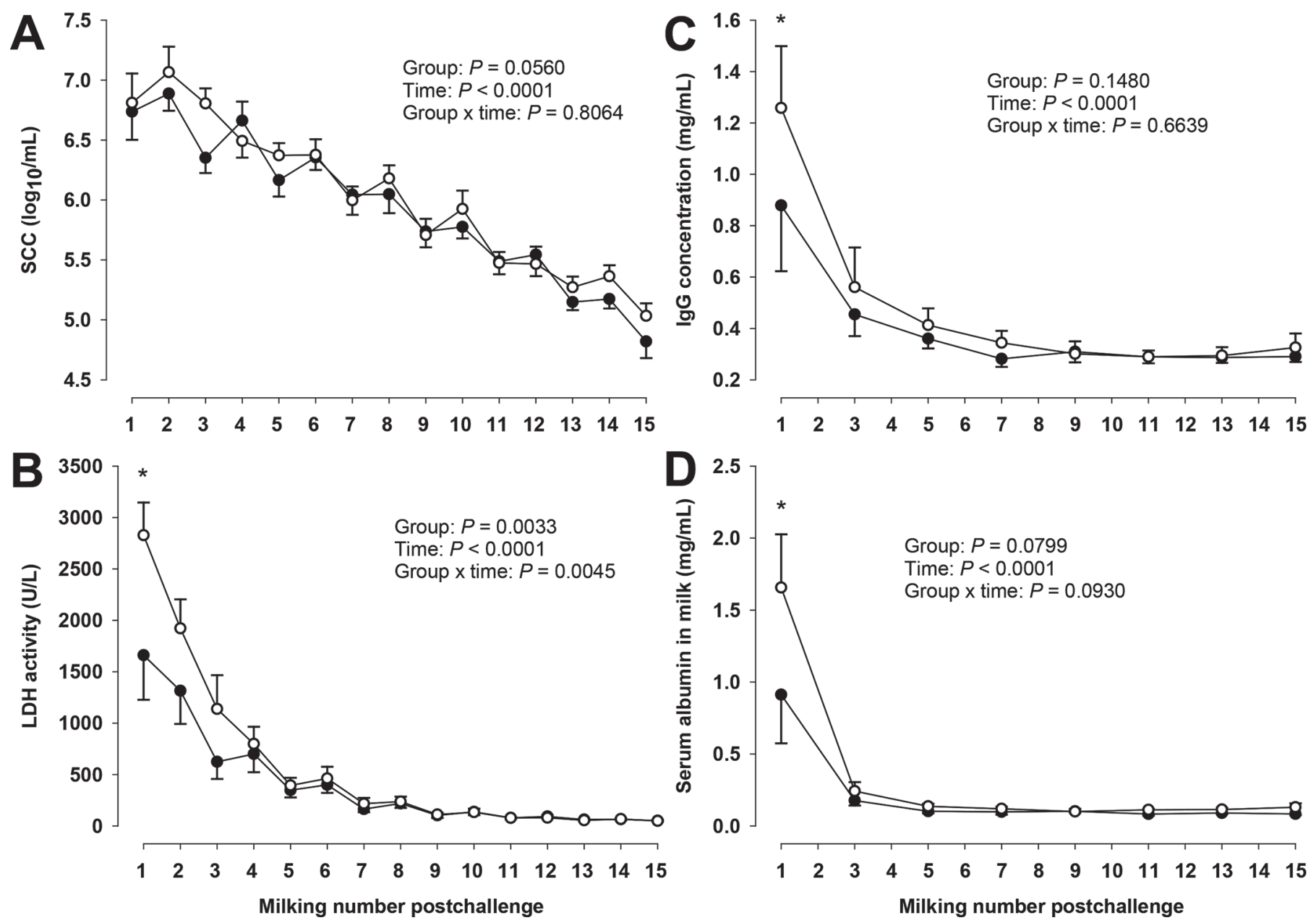

Figure 8. (A) Somatic cell count, (B) activity of lactate dehydrogenase (LDH), (C) IgG concentration, and (D) serum albumin concentration in milk of the LPS-stimulated quarter in dairy cows assigned to the low-glucose (LG; $\mathrm{n}=8$ ) and high-glucose (HG; $\mathrm{n}=7$ ) groups during the 15 milkings after the day of the intramammary LPS challenge. Data are presented as means \pm SEM. Asterisks indicate differences within a milking between LG and HG $(P<0.05)$. 
milk yield compared with moderate responders with a concomitant better metabolic status (Vandeputte-Van Messom et al., 1993).

Reduced feed intake during mastitis increases the metabolic load with a further negative effect on the immune system. Concomitantly with a reduced milk yield following a mastitis induction, several studies reported a decline (Waldron et al., 2006; Moyes et al., 2014; Pires et al., 2019) or no changes in DMI (e.g., Shuster et al., 1991), whereas others did not report changes in DMI at all (e.g., Hoeben et al., 2000). Although it is known that cows are anorectic during acute coliform mastitis (Shuster et al., 1991), data on the associations of the concomitant metabolic status and its interactions with DMI changes are scarce. A rapid recovery of DMI is desirable to support energy intake and supply for the immune system. Cows in the present study with low glucose concentrations achieved their prechallenge feed intake level $2 \mathrm{~d}$ after the LPS-CH, whereas HG cows had already recovered at the following day. Our results demonstrate the importance of glucose availability not only for the inflammatory response but also for the recovery after inflammation.

In the present study, cows in the HG group recovered faster in milk yield and DMI and restored the bloodmilk barrier more rapidly compared with LG cows. It is speculated that feed restriction and metabolic stress reduce the integrity of the blood-milk barrier by the exfoliation of mammary epithelial cells (Stumpf et al., 2013; Herve et al., 2019). Similarly, LDH activity, IgG, and SA concentrations declined earlier in HG compared with LG, which suggests a more rapid recovery of the blood-milk barrier in cows at a better metabolic condition. Furthermore, milk SCC was higher in LG after the LPS-CH, which supports recent findings of greater milk SCC in cows exposed to feed restriction before an LPS-CH (Pires et al., 2019). The increased SCC during mastitis is mainly represented by polymorphonuclear neutrophils (Sarikaya et al., 2006), and they are the main effectors in the combat against pathogenic bacteria by a distinct capability of phagocytosis. As glucose is the preferred substrate for neutrophils (Pithon-Curi et al., 2004), differences in glucose availability in the animals of our study can be speculated to be associated with respective changes in milk SCC.

\section{CONCLUSIONS}

The metabolic status reflected by differences in glucose and BHB concentrations in early-lactating cows before the induction of a transient inflammatory state via an intramammary LPS-CH persisted throughout the experiment. Due to our classification criteria, circulating glucose concentration was the main dis- criminating factor besides ketone body concentration. Our results confirm earlier observations that both the limited availability of glucose and the inhibitory effect of elevated BHB concentrations are associated with the responses to an LPS-CH. Furthermore, we could demonstrate that a better metabolic condition was associated with an accelerated recovery pattern of the blood-milk barrier as well as milk production and feed intake. Therefore, improving the metabolic status in early-lactating cows can help limit the negative effect of infectious diseases such as mastitis on udder health and performance.

\section{ACKNOWLEDGMENTS}

This study was supported by a grant of the Swiss National Science Foundation (Bern, Switzerland; grant no. 176152). The authors have not stated any conflicts of interest.

\section{REFERENCES}

Aleri, J. W., B. C. Hine, M. F. Pyman, P. D. Mansell, W. J. Wales, B. Mallard, and A. D. Fisher. 2016. Periparturient immunosuppression and strategies to improve dairy cow health during the periparturient period. Res. Vet. Sci. 108:8-17. https://doi.org/10 .1016/j.rvsc.2016.07.007.

Bauman, D. E., and W. B. Currie. 1980. Partitioning of nutrients during pregnancy and lactation: A review of mechanisms involving homeostasis and homeorhesis. J. Dairy Sci. 63:1514-1529. https:// doi.org/10.3168/jds.S0022-0302(80)83111-0.

Blum, J. W., F. Jans, W. Moses, D. Fröhli, M. Zemp, M. Wanner, I. C. Hart, R. Thun, and U. Keller. 1985. Twenty-four-hour pattern of blood hormone and metabolite concentrations in high-yielding dairy cows: Effects of feeding low or high amounts of starch, or crystalline fat. Zentralbl. Veterinarmed. A 32:401-418. https://doi .org/10.1111/j.1439-0442.1985.tb01957.x.

Brickner, A. E., J. A. A. Pires, T. F. Gressley, and R. R. Grummer. 2009. Effects of abomasal lipid infusion on liver triglyceride accumulation and adipose lipolysis during fatty liver induction in dairy cows. J. Dairy Sci. 92:4954-4961. https://doi.org/10.3168/ jds.2009-2147.

Bruckmaier, R. M., and J. J. Gross. 2017. Lactational challenges in transition dairy cows. Anim. Prod. Sci. 57:1471-1481. https://doi .org/10.1071/AN16657.

Bruckmaier, R. M., M. Schällibaum, and J. W. Blum. 1993. Escherichia coli endotoxin-induced mastitis in dairy cows: Changes and importance of insulin-like growth factor I and oxytocin. Milchwissenschaft 48:374-378.

Brunner, N., S. Groeger, J. Canelas Raposo, R. M. Bruckmaier, and J. J. Gross. 2019. Prevalence of subclinical ketosis and production diseases in dairy cows in Central and South America, Africa, Asia, Australia and New Zealand, and Eastern Europe. Transl. Anim. Sci. 3:84-92. https://doi.org/10.1093/tas/txy102.

DePeters, E. J., and J. D. Ferguson. 1992. Nonprotein nitrogen and protein distribution in the milk of cows. J. Dairy Sci. 75:31923209. https://doi.org/10.3168/jds.S0022-0302(92)78085-0.

Drackley, J. K. 1999. Biology of dairy cows during the transition period: The final frontier? J. Dairy Sci. 82:2259-2273. https://doi .org/10.3168/jds.S0022-0302(99)75474-3.

Graugnard, D. E., K. M. Moyes, E. Trevisi, M. J. Khan, D. Keisler, J. K. Drackley, G. Bertoni, and J. J. Loor. 2013. Liver lipid content and inflammometabolic indices in peripartal dairy cows are altered in response to prepartal energy intake and postpartal intramam- 
mary inflammatory challenge. J. Dairy Sci. 96:918-935. https:// doi.org/10.3168/jds.2012-5676.

Gross, J., H. A. van Dorland, R. M. Bruckmaier, and F. J. Schwarz. 2011a. Performance and metabolic profile of dairy cows during a lactational and deliberately induced negative energy balance with subsequent realimentation. J. Dairy Sci. 94:1820-1830. https://doi . org $/ 10.3168 /$ jds.2010-3707.

Gross, J., H. A. van Dorland, F. J. Schwarz, and R. M. Bruckmaier. 2011b. Endocrine changes and liver mRNA abundance of somatotropic axis and insulin system constituents during negative energy balance at different stages of lactation in dairy cows. J. Dairy Sci. 94:3484-3494. https://doi.org/10.3168/jds.2011-4251.

Gross, J. J., and R. M. Bruckmaier. 2019. Invited review: Metabolic challenges and adaptation during different functional stages of the mammary gland in dairy cows: Perspectives for sustainable milk production. J. Dairy Sci. 102:2828-2843. https://doi.org/10.3168/ jds.2018-15713.

Gross, J. J., L. Grossen-Rösti, R. Héritier, A. Tröscher, and R. M. Bruckmaier. 2018. Inflammatory and metabolic responses to an intramammary lipopolysaccharide challenge in early lactating cows supplemented with conjugated linoleic acid. J. Anim. Physiol. Anim. Nutr. (Berl.) 102:e838-e848. https://doi.org/10.1111/jpn .12843 .

Grummer, R. R. 1993. Etiology of lipid-related metabolic disorders in periparturient dairy cows. J. Dairy Sci. 76:3882-3896. https://doi .org/10.3168/jds.S0022-0302(93)77729-2.

Gustafsson, A. H., and D. L. Palmquist. 1993. Diurnal variation of rumen ammonia, serum urea, and milk urea in dairy cows at high and low yields. J. Dairy Sci. 76:475-484. https://doi.org/10.3168/ jds.S0022-0302(93)77368-3.

Han van der Kolk, J. H., J. J. Gross, V. Gerber, and R. M. Bruckmaier. 2017. Disturbed bovine mitochondrial lipid metabolism: A review. Vet. Q. 37:262-273. https://doi.org/10.1080/01652176 .2017 .1354561 .

Herve, L., H. Quesnel, M. Veron, J. Portanguen, J. J. Gross, R. M. Bruckmaier, and M. Boutinaud. 2019. Milk yield loss in response to feed restriction is associated with mammary epithelial cell exfoliation in dairy cows. J. Dairy Sci. 102:2670-2685. https://doi.org/ 10.3168/jds.2018-15398.

Hoeben, D., C. Burvenich, E. Trevisi, G. Bertoni, J. Hamann, R. M. Bruckmaier, and J. W. Blum. 2000. Role of endotoxin and TNFalpha in the pathogenesis of experimentally induced coliform mastitis in periparturient cows. J. Dairy Res. 67:503-514. https://doi .org/10.1017/S0022029900004489.

Holtenius, K., K. Persson Waller, B. Essén-Gustavsson, P. Holtenius, and C. Hallén Sandgren. 2004. Metabolic parameters and blood leucocyte profiles in cows from herds with high or low mastitis incidence. Vet. J. 168:65-73. https://doi.org/10.1016/S1090 -0233(03)00180-1.

Ingvartsen, K. L., and K. M. Moyes. 2015. Factors contributing to immunosuppression in the dairy cow during the periparturient period. Jpn. J. Vet. Res. 63(Suppl. 1):S15-S24.

Kremer, W. D. J., E. N. Noordhuizen-Stassen, F. J. Grommers, Y. H. Schukken, R. Heeringa, A. Brand, and C. Burvenich. 1993. Severity of experimental Escherichia coli mastitis in ketonemic and nonketonemic dairy cows. J. Dairy Sci. 76:3428-3436. https://doi .org/10.3168/jds.S0022-0302(93)77681-X.

Kvidera, S. K., E. A. Horst, M. Abuajamieh, E. J. Mayorga, M. V. Fernandez, and L. H. Baumgard. 2017. Glucose requirements of an activated immune system in lactating Holstein cows. J. Dairy Sci. 100:2360-2374. https://doi.org/10.3168/jds.2016-12001.

Lee, J. Y., A. Plakidas, W. H. Lee, A. Heikkinen, P. Chanmugam, G. Bray, and D. H. Hwang. 2003. Differential modulation of Toll-like receptors by fatty acids: Preferential inhibition by n-3 polyunsaturated fatty acids. J. Lipid Res. 44:479-486. https://doi.org/10 .1194/jlr.M200361-JLR200.

Lehmann, M., O. Wellnitz, and R. M. Bruckmaier. 2013. Concomitant lipopolysaccharide-induced transfer of blood-derived components including immunoglobulins into milk. J. Dairy Sci. 96:889-896. https://doi.org/10.3168/jds.2012-5410.
Lehtolainen, T., S. Suominen, T. Kutila, and S. Pyörälä. 2003. Effect of intramammary Escherichia coli endotoxin in early- vs. latelactating dairy cows. J. Dairy Sci. 86:2327-2333. https://doi.org/ 10.3168/jds.S0022-0302(03)73825-9.

Moyes, K. M. 2015. Nutrient partitioning during intramammary inflammation: A key to severity of mastitis and risk of subsequent diseases? J. Anim. Sci. 93:5586-5593. https://doi.org/10.2527/jas .2015-8945.

Moyes, K. M., T. Larsen, P. Sørensen, and K. L. Ingvartsen. 2014. Changes in various metabolic parameters in blood and milk during experimental Escherichia coli mastitis for primiparous Holstein dairy cows during early lactation. J. Anim. Sci. Biotechnol. 5:47. https://doi.org/10.1186/2049-1891-5-47.

Nguyen, D. A., and M. C. Neville. 1998. Tight junction regulation in the mammary gland. J. Mammary Gland Biol. Neoplasia 3:233246. https://doi.org/10.1023/A:1018707309361.

Oliver, S. P., and L. F. Calvinho. 1995. Influence of inflammation on mammary gland metabolism and milk composition. J. Anim. Sci. 73(Suppl. 2):18-33. https://doi.org/10.2527/1995.73suppl_218x.

Perkins, K. H., M. J. VandeHaar, J. L. Burton, J. S. Liesman, R J. Erskine, and T. H. Elsasser. 2002. Clinical responses to intramammary endotoxin infusion in dairy cows subjected to feed restriction. J. Dairy Sci. 85:1724-1731. https://doi.org/10.3168/jds .S0022-0302(02)74246-X.

Pires, J. A. A., K. Pawlowski, J. Rouel, C. Delavaud, G. Foucras, P. Germon, and C. Leroux. 2019. Undernutrition modified metabolic responses to intramammary lipopolysaccharide but had limited effects on selected inflammation indicators in early-lactation cows. J. Dairy Sci. 102:5347-5360. https://doi.org/10.3168/jds.2018-15446.

Pithon-Curi, T. C., M. P. De Melo, and R. Curi. 2004. Glucose and glutamine utilization by rat lymphocytes, monocytes and neutrophils in culture: A comparative study. Cell Biochem. Funct. 22:321-326. https://doi.org/10.1002/cbf.1109.

Potter, T. L., C. Arndt, and A. N. Hristov. 2018. Short communication: Increased somatic cell count is associated with milk loss and reduced feed efficiency in lactating dairy cows. J. Dairy Sci. 101:9510-9515. https://doi.org/10.3168/jds.2017-14062.

Sarikaya, H., G. Schlamberger, H. H. Meyer, and R. M. Bruckmaier. 2006. Leukocyte populations and mRNA expression of inflammatory factors in quarter milk fractions at different somatic cell score levels in dairy cows. J. Dairy Sci. 89:2479-2486. https://doi.org/ 10.3168/jds.S0022-0302(06)72322-0.

Schwinn, A. C., C. H. Knight, R. M. Bruckmaier, and J. J. Gross. 2016. Suitability of saliva cortisol as a biomarker for hypothalamic-pituitary-adrenal axis activation assessment, effects of feeding actions, and immunostimulatory challenges in dairy cows. J. Anim. Sci. 94:2357-2365. https://doi.org/10.2527/jas.2015-0260.

Shuster, D. E., R. J. Harmon, J. A. Jackson, and R. W. Hemken. 1991. Suppression of milk production during endotoxin-induced mastitis. J. Dairy Sci. 74:3763-3774. https://doi.org/10.3168/jds S0022-0302(91)78568-8.

Sjaunja, L. O., L. Baevre, L. Junkkarinen, J. Pedersen, and J. Setäla. 1990. A Nordic proposal for an energy corrected milk (ECM) formula. Pages 156-157 in Performance Recording of Animals: State of the Art, 1990: Proceedings of the 27th Biennial Session of the International Committee for Animal Recording (ICAR), Paris, France. J. A. M. van Arendonk, ed. Wageningen Academic Publishers, Wageningen, the Netherlands.

Sordillo, L. M., G. A. Contreras, and S. L. Aitken. 2009. Metabolic factors affecting the inflammatory response of periparturient dairy cows. Anim. Health Res. Rev. 10:53-63. https://doi.org/10.1017/ S1466252309990016.

Stumpf, M. T., V. Fischer, C. M. McManus, G. J. Kolling, M. B. Zanela, C. S. Santos, A. S. Abreu, and P. Montagner. 2013. Severe feed restriction increases permeability of mammary gland cell tight junctions and reduces ethanol stability of milk. Animal 7:11371142. https://doi.org/10.1017/S1751731113000128.

Suriyasathaporn, W., A. J. Daemen, E. N. Noordhuizen-Stassen, S. J. Dieleman, M. Nielen, and Y. H. Schukken. 1999. Beta-hydroxybutyrate levels in peripheral blood and ketone bodies supplemented 
in culture media affect the in vitro chemotaxis of bovine leukocytes. Vet. Immunol. Immunopathol. 68:177-186. https://doi.org/ 10.1016/S0165-2427(99)00017-3.

Suthar, V. S., J. Canelas-Raposo, A. Deniz, and W. Heuwieser. 2013. Prevalence of subclinical ketosis and relationships with postpartum diseases in European dairy cows. J. Dairy Sci. 96:2925-2938. https://doi.org/10.3168/jds.2012-6035.

Targowski, S. P., and W. Klucinski. 1983. Reduction in mitogenic response of bovine lymphocytes by ketone bodies. Am. J. Vet. Res. 44:828-830.

Trevisi, E., M. Amadori, S. Cogrossi, E. Razzuoli, and G. Bertoni. 2012. Metabolic stress and inflammatory response in high-yielding, periparturient dairy cows. Res. Vet. Sci. 93:695-704. https://doi .org/10.1016/j.rvsc.2011.11.008

Tsunoda, E., J. J. Gross, C. Kawashima, R. M. Bruckmaier, K. Kida, and A. Miyamoto. 2017. Feed-derived volatile basic nitrogen increases reactive oxygen species production of blood leukocytes in lactating dairy cows. Anim. Sci. J. 88:125-133. https://doi.org/10 $.1111 /$ asj.12608.

Vandeputte-Van Messom, G., C. Burvenich, E. Roets, A. M. MassartLeën, R. Heyneman, W. D. Kremer, and A. Brand. 1993. Classification of newly calved cows into moderate and severe responders to experimentally induced Escherichia coli mastitis. J. Dairy Res. 60:19-29. https://doi.org/10.1017/S002202990002731X.

Vernay, M. C. M. B., O. Wellnitz, L. Kreipe, H. A. van Dorland, and R. M. Bruckmaier. 2012. Local and systemic response to intramammary lipopolysaccharide challenge during long-term manipulated plasma glucose and insulin concentrations in dairy cows. J. Dairy Sci. 95:2540-2549. https://doi.org/10.3168/jds.2011-5188.

Vicari, T., J. J. G. C. van den Borne, W. J. J. Gerrits, Y. Zbinden, and J. W. Blum. 2008. Postprandial blood hormone and metabolite concentrations influenced by feeding frequency and feeding level in veal calves. Domest. Anim. Endocrinol. 34:74-88. https://doi.org/ 10.1016/j.domaniend.2006.11.002

Waldron, M. R., A. E. Kulick, A. W. Bell, and T. R. Overton. 2006. Acute experimental mastitis is not causal toward the development of energy-related metabolic disorders in early postpartum dairy cows. J. Dairy Sci. 89:596-610. https://doi.org/10.3168/jds.S0022 -0302(06)72123-3.

Wellnitz, O., E. T. Arnold, and R. M. Bruckmaier. 2011. Lipopolysaccharide and lipoteichoic acid induce different immune responses in the bovine mammary gland. J. Dairy Sci. 94:5405-5412. https:// doi.org/10.3168/jds.2010-3931.

Wellnitz, O., and R. M. Bruckmaier. 2012. The innate immune response of the bovine mammary gland to bacterial infection. Vet. J. 192:148-152. https://doi.org/10.1016/j.tvjl.2011.09.013.

Wellnitz, O., C. Zbinden, X. Huang, and R. M. Bruckmaier. 2016. Short communication: Differential loss of bovine mammary epithelial barrier integrity in response to lipopolysaccharide and lipoteichoic acid. J. Dairy Sci. 99:4851-4856. https://doi.org/10.3168/ jds.2016-10927.

Zamet, C. N., V. F. Colenbrander, R. E. Erb, C. J. Callahan, B. P. Chew, and N. J. Moeller. 1979. Variables associated with peripartum traits in dairy cows. II. Interrelationships among disorders and their effects on intake of feed and on reproductive efficiency. Theriogenology 11:245-260. https://doi.org/10.1016/0093 -691X(79)90032-3.

Zarrin, M., O. Wellnitz, H. A. van Dorland, J. J. Gross, and R. M. Bruckmaier. 2014. Hyperketonemia during lipopolysaccharide-induced mastitis affects systemic and local intramammary metabolism in dairy cows. J. Dairy Sci. 97:3531-3541. https://doi.org/10 $.3168 /$ jds.2013-7480.

\section{ORCIDS}

J. J. Gross $\odot$ https://orcid.org/0000-0002-2578-6076

S. K. Wall $\odot$ https://orcid.org/0000-0002-5734-6999

O. Wellnitz (ㄴ) https://orcid.org/0000-0002-5817-3428

R. M. Bruckmaier ( https://orcid.org/0000-0002-9374-5890 